\title{
To Boycott or Not to Boycott
}

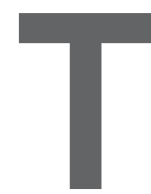

HERE HAS BEEN SOUnd and fury in the Open Access movement over the past year. In December 2011, The Research Works Act (RWA) was introduced in the U.S. House of Representatives. The bill contained provisions to prohibit open access mandates for federally funded research, effectively nullifying the U.S. National Institutes of Health's policy that requires taxpayer-funded research to be freely accessible online. Many scholarly publishers, including the Association of American Publishers (AAP), expressed support for the bill. (ACM expressed objections to the bill.)

The reaction to the bill and its support by scholarly publishers has been one of sheer outrage, with headlines such as "Academic Publishers Have Become the Enemies of Science." On January 21,2012 , renowned British mathematician Timothy Gowers declared a boycott on Elsevier, a major scholarly publisher, pledging to refrain from submitting articles to Elsevier journals, as well as from serving as an editor or reviewer. The boycott movement then took off, with over 13,000 scholars having joined so far.

Frankly, I do not understand why Elsevier is practically the sole target of the recent wrath directed at scholarly publishers. Elsevier is no worse than most other for-profit publishers, just bigger, I believe. Why boycott Elsevier and not Springer, for example? The argument made by some that "we must start somewhere" strikes me as plainly unfair and unjust.

Beyond the question of whom to target with a boycott, there is the question of the morality of the boycott. Of course, authors can choose their publication venues. Also, as a scholar, I can choose which publications I am willing to support by becoming an editor, but the boycott petition also asks signato- ries to refrain from refereeing articles submitting to Elsevier journals. This means that if you sign this petition then, in effect, you are boycotting your colleagues who have disagreed with you and chose to submit their articles to an Elsevier journal.

I believe in keeping science separate from politics. If it is legitimate to boycott publishing politics - the issue of open access is, after all, a political issue - why is it not legitimate to boycott for other political considerations? Is it legitimate to refrain from refereeing articles written by authors from countries with objectionable government behavior? Where do you draw the line to avoid politicizing science?

My perspective is that what really propelled the Open Access movement was the continuing escalation of the price of scholarly publications during the 1990s and 2000s, a period during which technology drove down the cost of scientific publishing. This price escalation has been driven by for-profit publishers. In the distant past, our field had several small- and medium-sized for-profit publishers. There was a sense of informal partnership between the scientific community and these publishers. That was then. Today, there is a small number of large and dominant for-profit publishers in computing research. These publishers are thoroughly corporatized. They are businesses with a clear mission of maximizing the return on investment to their owners

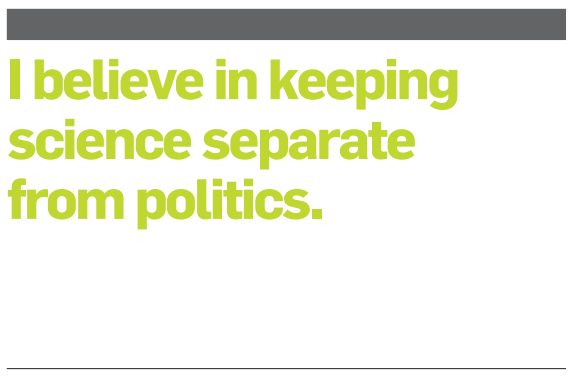

and shareholders. At the same time, the scientific community, whose goal is to maximize dissemination, continues to behave as if a partnership exists with for-profit publishers, providing them with content and editorial services essentially gratis. This is a highly anomalous arrangement, in my opinion. Why should for-profit corporations receive products and labor essentially for free?

Beyond the moral issue I raised earlier regarding the boycott, there is a more practical issue. For-profit publishers play a key role in computingresearch publishing. As an example, approximately 45,000 journal articles were published in 2011 in computing research. In that same year, ACM published fewer than 1,000 journal articles, and IEEE-Computer Society published fewer than 3,500 articles. There is a small number of other non-profit publishers, but for-profit publishers produce the lion's share of computingresearch journal articles. Boycotting all of them is simply not a practical option.

I do not believe, therefore, that boycotting is the right approach to the current scholarly publishing controversies. If we want to drive for-profit publishers out of business, we have to do it the oldfashioned way, by out-publishing them. If professional associations in computing research would expand their publishing activities considerably, they should be able to attract the bulk of computing articles. ACM is only a minor player in journal publishing. Why is ACM publishing fewer than 1,000 journal articles per year rather than, say, 5,000 articles? Even if this will not drive the for-profit publishers out of the computing-research publishing business, the competition would pressure them to reform their business practices, which is, after all, what we should be after.

Moshe Y. Vardi, EDITOR-IN-CHIE F 